\title{
ARQUEOLOGIA DA QUESTÃo AGRÁRIA NO BRASIL: do labor grabbing ao land grabbing
}

\section{ARCHEOLOGIE DE LA QUESTION AGRAIRE AU BRESIL: du labor grabbing au land grabbing}

\begin{abstract}
Cássio Arruda Boechat
Professor do Departamento de Geografia e do Programa de Pós-graduação em Geografia da Universidade Federal do Espírito Santo. Tradutor e sociólogo, é mestre e doutor em Geografia Humana pela USP cassio.boechat@ufes.br

Carlos de Almeida Toledo

Professor do Departamento de Geografia e do Programa de Pós-graduação em Geografia Humana, da FFLCH/USP carlosdealmeidatoledo@gmail.com

Ana Carolina Gonçalves Leite Professora e pesquisadora do Programa de Pós-graduação em Geografia, do CCHN/UFES. Bolsista do PNPD/Capes carolinavecchia@gmail.com
\end{abstract}

\section{Resumo}

O artigo procura repensar a trajetória histórica de constituição das regiões no Brasil por meio de uma dupla conceituação acerca dos procedimentos de expropriação, centrados ora na escravidão (labor grabbing) ora na apropriação privada da terra (land grabbing). Por este meio, retoma-se criticamente autores clássicos que lidaram com a formação nacional, propondo alternativamente lidar com a modernização através da noção de autonomização do capital. Com isso, espera-se produzir uma abordagem teórica sobre a constituição da questão agrária no Brasil como decorrente do processo que, por meio da integração nacional, busca tratar a região como problema a ser solucionado.

Palavras-chave: Região. Colonização sistemática. Labor grabbing. Land grabbing. Autonomização do capital.

\section{Résumé}

Cet article cherche à repenser la trajectoire historique de constitution des régions du Brésil par une double conceptualisation des procédures d'expropriation, centrées soit sur l'esclavage (labor grabbing), soit sur l'appropriation privée de la terre (land grabbing). De cette façon sont repris des auteurs classiques qui ont travaillé sur la formation nationale, tout en proposant alternativement d'aborder la modernisation par la notion d'autonomisation du capital. Nous souhaitons ainsi produire une approche théorique sur la constitution de la question agraire au Brésil comme découlant du processus qui, par l'intégration nationale, aborde la région comme un problème à régler.

CAMPO-TERRITÓRIO: revista de geografia agrária, v. 13, n. 31, p. 57-82, dez., 2018 
Mots-clés: Région. Colonisation systématique. Labor grabbing. Land grabbing. Autonomisation du capital.

\section{Introdução}

Encontrando a literatura sobre a questão agrária brasileira assentada num dualismo que contrapõe aspectos de um atraso a possibilidades da "nossa" modernização, consideramos a necessidade de uma crítica abrangente ao dualismo. Assim, o percurso será o de repensar o conceito de "região" (OLIVEIRA, 2008; TOLEDO e BOECHAT, 2012; LEITE, 2014) em processo desde a região colonial à sua incorporação ao planejamento estatal. Isso advém da preocupação em qualificar colonização e a constituição de regiões para não cair em caracterizações baseadas em oposições à contemporaneidade. Tomamos, com isso, duas questões a serem pensadas. A primeira, de que a modernização se pauta numa autonomização (MARX, 1985) das categorias de terra, trabalho, Estado e capital, antes fundidas em personificações que reuniam mais de uma delas. A segunda de que a questão agrária se desdobra da questão regional e da oposição que emerge entre agricultura e indústria e entre rural e urbano, sendo importante retomar elementos negligenciados que condicionam a formação da primeira. Como não acreditamos que tais debates sejam datados, com posições dualistas ainda rebatendo na produção intelectual recente sobre o "mundo rural", reiteramos a necessidade dessa crítica. Nossa "arqueologia" busca encontrar, assim, o sentido de um espectro que ronda a questão agrária contemporânea.

Relacionaremos a questão agrária à questão regional apresentando a autonomização do capital como um desdobramento que fragmenta o processo de trabalho e de valorização do capital em mediações de muitos mercados e em especial ao consolidar um mercado fundiário, um de trabalho e um de dinheiro, nacionalmente, apartados entre si e separados do Estado. Assim, a industrialização e a urbanização do território supõem a constituição do mercado de capitais e requerem a provisão de matérias-primas, trabalhadores disponíveis, além da intermediação do crédito para alavancar os investimentos, com o Estado nacional centralizado mediando seus mais diversos elos. Retemos, todavia, a ideia de que a autonomização realiza apenas a constituição de uma aparência necessária de autonomia (MARX, 1986), de maneira que a valorização do capital segue dependendo da exploração de trabalhadores, não havendo como as demais

CAMPO-TERRITÓRIO: revista de geografia agrária, v. 13, n. 31, p. 57-82, dez., 2018 
categorias (terra, capital e Estado) se auto-remunerarem sem tal pré-requisito, ainda que ele ocorra em outras paragens que não naquela em que se encontra o elemento remunerado. Esse desdobramento dos diferentes mercados constitui, ao mesmo tempo, a generalização de uma forma social única que passa pelo mercado e pela redução de pessoas, lugares e coisas à qualidade genérica de mercadorias ou proprietários delas. Assim, podemos tratar a autonomização também como processo de homogeneização dessa forma social fetichista. Desse modo, o par heterogeneidade/homogeneidade organiza as fideias seguintes, evitando atestar com pressa a prevalência de um dos polos sobre o outro.

Sendo assim, este artigo procura repensar a trajetória histórica de constituição das regiões no Brasil, tratadas adiante como formas particulares de reprodução das relações sociais de produção, por meio de uma dupla conceituação acerca dos procedimentos de expropriação, centrados em um primeiro momento na escravidão (labor grabbing), em que não existem mercados de terra, trabalho e capital autonomizados, e finalmente na apropriação privada da terra (land grabbing), que segundo Marx, em oposição aos escravos, é a última a apresentar-se como figura intercambiável por dinheiro (MARX, 1985, Livro I, cap. 2, p. 213). A particularidade abordada indicará que eventualmente nem um nem o outro explicam exatamente o que mobiliza o trabalho no interior da região. Por este meio, retoma-se criticamente autores clássicos que lidaram com a formação nacional, propondo alternativamente lidar com a modernização através da noção marxiana de autonomização do capital. Com isso, embora o texto represente uma síntese de diversas pesquisas feitas pelos autores sobre regiões particulares, espera-se produzir aqui sobretudo uma abordagem teórica sobre a constituição da questão agrária no Brasil como decorrente do processo que, por meio da integração nacional, busca tratar a região como problema a ser solucionado.

\section{Questão regional e questão agrária}

Não é novidade que "região" foi o conceito que embasou e caracterizou a Geografia Tradicional, especialmente aquela inspirada por autores franceses de fins do século XIX e da primeira metade do século XX, sendo tratada como síntese particular da relação entre homem e meio que devesse ser descrita monograficamente, e que tal 
conceito e método foram alvos de críticas variadas a partir dos anos 1950/1960 (ver SANTOS, 2008). Retomaremos aqui, no entanto, uma abordagem que repensou criticamente o conceito de região sem abandoná-lo, delineando-o como elemento particular de uma totalidade contraditória ou parte da divisão internacional do trabalho, incluindo uma importante dimensão do poder ou da dominação aparentemente política na sua caracterização.

Francisco de Oliveira (2008) propôs um tratamento para a chamada questão regional que contribuiu para organizar uma história de controvérsias interpretativas e processos sociais que condicionaram o debate em torno da questão agrária brasileira. Ele indicava um rumo da modernização que rompia com as regiões e instaurava uma tendência de homogeneização das relações sociais de produção a qual acabaria por delimitar só desigualdades regionais, de modo a constituir "zonas de localização diferencial" como figurado no desenvolvimento que identificou nos EUA:

[...] existe uma tendência para a completa homogeneização da reprodução do capital, que acabaria por fazer desaparecer as "regiões", no sentido proposto por esta investigação. [...] Tal tendência quase nunca chega a materializar-se de forma completa e acabada, pelo próprio fato de que o processo de reprodução do capital é por definição desigual e combinado, mas em alguns espaços econômicos do mundo capitalista, de que talvez a economia norte-americana seja o exemplo mais completo, é inegável o grau de homogeneização propiciado pela concentração e centralização do capital, de forma a quase borrar por inteiro as diferenças entre os vários segmentos do território nacional norte-americano (OLIVEIRA, 2008, p. 146).

Tratando, portanto, a incidência da modernização sobre regiões rurais como uma dinâmica homogeneizante nos caberia indagar quais conteúdos eram modificados e sob quais critérios a dinâmica imposta os igualava. Em poucas palavras, o que é a região? Como e por que ela muda? O que qualifica o espaço oriundo da autonomização (MARX, 1986)? Retomar tais perguntas permite introduzir os pressupostos que rondaram os debates sobre a questão agrária. O leitor atento perceberá que a mesma pergunta retorna hoje com feições novas: o que é o (novo) rural? Como e por que ele se transforma? (ver BUAINAIN, ALVES, SILVEIRA e NAVARRO, 2014; WANDERLEY, 2013; CARNEIRO, 2008; entre outros). Comecemos com a resposta daquele autor: 
O "fechamento" de uma região pelas suas classes dominantes requer, exige e somente se dá, portanto, enquanto essas classes dominantes conseguem reproduzir a relação social de dominação, ou mais claramente as relações de produção. [...]. A "abertura" da região e a consequente "integração" nacional, no longo caminho até a dissolução completa das regiões, ocorre quando a relação social não pode mais ser reproduzida e, por essa impossibilidade, percola a perda de hegemonia das classes dominantes locais e sua substituição por outras, de caráter nacional e internacional. (OLIVEIRA, 2008, p. 151-2).

Vemos aí uma definição que qualifica a região, de modo distinto do que a Geografia regional, segundo sua dificuldade de definição - daí a sugestão de "uma forma especial de reprodução do capital" (OLIVEIRA, 2008, p. 151) -, porém sugerindo uma conformação territorial que teria, no fundo, o sentido de evitar a livre "mobilidade do trabalho" (GAUDEMAR, 1977), representando como que uma armadura - armature, conforme a definição de Lipietz (1988) em O capital e seu espaço, que teoriza de modo semelhante o conceito (ver SEABRA e GOLDENSTEIN, 1982) - que "fecha" politicamente a região, pressupondo tensões intra- e inter-regionais e com o Estado nacional em formação.

No que tange ao conteúdo social da região teríamos uma realidade que, pressupostas as categorias cindidas do pensamento, poderia ser qualificada como fundindo o poder econômico e político (OLIVEIRA, 2008); ou as esferas privada e pública (LEAL, 1976); ou mesclando violência extra-econômica e violência do mercado (RANGEL, 1986). Numa leitura mais abrangente, poderíamos repensar os modos pelos quais se caracterizariam os "bloqueios" ao livre exercício da mobilidade do trabalho para além da mera coerção física, de modo que as relações sociais que se estabeleciam regionalmente implicavam, como proposto por Maria Sylvia de Carvalho Franco (1997), em elementos de uma dominação pessoal que incluíam parentesco e parentela política, conforme também destacado na sociologia do coronelismo (QUEIROZ, 1976). Enquanto Sergio Buarque de Holanda (1995) observava a proeminência da pessoalidade sobre leis impessoais a caracterizar a "cordialidade" que remetia ao primado do "favor" sobre o “contrato" (SCHWARZ, 2000), Raymundo Faoro (1989) teorizaria a instituição do "patrimonialismo" no qual propriedade e estrutura fundiárias fundavam a sociabilidade.

De fato, o acesso parcial e mediado aos meios de produção pelos trabalhadores, caracterizados amplamente como "agregados", mas regionalmente assumindo formas

CAMPO-TERRITÓRIO: revista de geografia agrária, v. 13, n. 31, p. 57-82, dez., 2018 
particulares (colono, morador, vaqueiro, etc.), articulado àquele acesso às relações pessoais com os fazendeiros e às capacidades de coerção concentradas nesses últimos e cedidas pelo Estado compunham um cenário de difícil definição. Para Ignácio Rangel (1986), tratava-se de um feudalismo tradicionalista. José de Souza Martins (1998) e Ariovaldo U. de Oliveira (1987) observavam relações não especificamente capitalistas que repunham o campesinato no pós-colonial. De outro modo, para Caio Prado Jr. (1979), Vinícius Caldeira Brant (1976) e Maria Conceição D’Incao (1979), existiam formas disfarçadas do assalariamento, com a meação ou parceria rebaixando os custos da produção em épocas de crise. Celso Furtado (2000), por sua vez, optara por distinguir três setores da economia nacional: subsistência, exportação agrária e manufatura. A aparente neutralidade da distinção, todavia, revelava sua preocupação com a "regressão econômica" das regiões nas crises, quando perdiam o dinamismo dado pela inserção no mercado, voltando-se à produção para subsistência.

Temos, com isso, um controverso debate nacional de um conceito caro à Geografia tradicional. Para a Geografia regional francesa a região surgia especificando um "gênero de vida" (LENCIONI, 1999). Por isso, Pierre Monbeig (1998), em sua tese sobre a cafeicultura paulista, persegue constantemente dados para averiguar a constituição de uma região: particular relação com o meio, transformando-o de paisagem natural em cultural; sentimento de pertencimento; relativa estabilidade das relações sociais. Embora também essa Geografia viesse a servir aos propósitos da colonização e integração nacional, mapeando recursos e potencialidades econômicas dos territórios (MORAES, 2003), observamos a concepção de um olhar que busca pela heterogeneidade, num quadro diversificado de "gêneros de vida" em sua relação ecológica (SORRE, 1988) com o meio. Entretanto, sobretudo a partir das leituras críticas dos intelectuais de 1930 em diante (JACKSON, 2007), haveria a qualificação dessa heterogeneidade como formas particulares de dominação social, logo originando uma questão regional ora tratada pelo prisma de suas desigualdades ora pelo dos entraves que supostamente eram produzidos à modernização (OLIVEIRA, 1993).

Noutros trabalhos (TOLEDO, 2008; TOLEDO e BOECHAT, 2012; BOECHAT, 2014; LEITE, 2014 e LEITE, 2015) pudemos reconsiderar o dualismo inerente à dicotomia atraso/moderno como historicamente situado na inflexão dada à modernidade pelos padrões de sociabilidade do Estado moderno, oriundo da Revolução Francesa, e 
pelos padrões de produtividade do capital, oriundo da Revolução Industrial inglesa. Esta proposta passou pela releitura dos clássicos acima citados, evitando seus dualismos e aproveitando elementos que permitam a compreensão de relações particulares.

Desse modo, a perspectiva aqui adotada concebe um conceito de região que não seria nem aquele pejorativamente oposto à indústria e à metrópole, tampouco aquele da perspectiva supostamente neutra do planejamento estatal - materializada sobretudo pelo Instituto Brasileiro de Geografia e Estatística (IBGE) e, por longo período, influenciada por certa Geografia quantitativa -, e menos ainda pretende retomar o conceito-chave da Geografia tradicional, pensado como gênero de vida situado em determinada região natural. É assim que chegamos à reavaliação de formulações clássicas sobre a questão regional a rebater numa questão agrária no Brasil. Sugerimos um conceito que remete ao processo contraditório de territorialização das relações sociais de produção capitalistas que, no Brasil, reclamamos incluir a colonização do Antigo Regime no debate.

\section{Labor grabbing como fundamento da colonização do Antigo Regime}

Retomando as obras de Caio Prado Jr. (2000) e Fernando Novais (2005), a Colônia surgia moderna desde o início, posto que integrada à expansão do mercado europeu e empreendimento do Estado absolutista português. A explicação do "sentido da colonização" em torno da mercadoria, que soa "economicista" a princípio, permite retomar o fundamento marxiano da forma mercadoria como "abstração real" (MARX, 1985). Assim, embora a produção de mercadorias tropicais, sob o monopólio metropolitano, com trabalho escravo e em grandes cessões de terras, diferisse radicalmente das manufaturadas inglesas, feitas em indústrias privadas e com assalariados, ambas viriam a se igualar no mercado, movendo mediante a troca e a produção para a troca o apagamento social das suas condições sociais de (re)produção. Tal mecanismo de abstração reiterado na prática caracteriza o substrato da impessoalidade do mercado. Constituição e generalização das práticas mediadas por mercadorias e, assim, pelo mercado, condiziriam, em sua impessoalidade e abstração, com a disseminação de certo individualismo assente na tendência ao reconhecimento dos trabalhadores como cidadãos. Momento necessário desse reconhecimento é o do direito deles à propriedade privada de seus próprios corpos e da capacidade produtiva contida

CAMPO-TERRITÓRIO: revista de geografia agrária, v. 13, n. 31, p. 57-82, dez., 2018 
neles. Assim, o trabalhador livre que se aluga no mercado é categoria social moderna em formação, algo que só viria a se generalizar e ter reconhecimento social nalgumas realidades em fins do século XVIII (FRANCO, 1984). Contudo, havendo simultaneidade dessa constituição com a realidade colonial, os laços que conectavam tais "mundos", na aparência apartados, não se restringiam a trocas imediatas.

O "exclusivo metropolitano" se mostrava como mecanismo de acumulação a explicitar a posição desigual entre Metrópole e Colônia, bem como o monopólio sobre o corpo do trabalhador escravizado evidenciava posição totalmente desigual e hierárquica entre senhor e escravo. Neste ponto, ainda não se diferem substancialmente a situação de indígenas e africanos, algo que processualmente caminharia para uma "questão racial" (VAINER, 1984; QUIJANO, 2005) construída, de um lado, pela "guerra dos bárbaros" a escravizar as populações e "pacificar" as terras indígenas (PUNTONI, 2002) e, de outro, pela conformação da escravidão negreira como importante mecanismo de acumulação de capital para a metrópole (ALENCASTRO, 2005). Ou, como preferiu Gilberto Freyre (2000), uma colonização conduzida pela “iniciativa privada de espada nas mãos”. Porém, uma na qual tal iniciativa seria amarrada aos interesses do governo metropolitano (FAORO, 1989). A conquista territorial forçada e a reprodução da Colônia colocavam às claras o papel central da violência de mobilizar forçadamente o trabalho e realizar o "sentido profundo da colonização", a acumulação de capital na Europa (NOVAIS, 2005, p. 70): “Completa-se, entrementes, a conotação do sentido profundo da colonização: comercial e capitalista, isto é, elemento constitutivo no processo de formação do capitalismo moderno".

Tal processo na Colônia diferiria, contudo, do caso "clássico" de acumulação primitiva, baseado este último na expulsão de camponeses, no cercamento de terras comunais (enclousures), numa legislação punitiva à vagabundagem e na coerção ao trabalho fabril (MARX, 1985, Livro I, cap. 24). O expediente central da acumulação primitiva inglesa era, portanto, o land grabbing, a apropriação privada da base fundiária levando à expropriação do povo.

$\mathrm{O}$ termo land grabbing remete à mudança rápida de propriedade ou de domínio, podendo se referir não apenas à terra, como também a patentes e market shares, e vem sendo utilizado, na língua portuguesa, como sinônimo de grilagem, estrangeirização de terras ou expropriação (ver CLEMENTS e FERNANDES, 2012, p. 3; OLIVEIRA, 2010; 
SAUER e LEITE, 2012), embora Sergio Sauer e Saturnino Borras Jr (2016, pp. 12-13) sugiram o termo "apropriação de terras" pela sua abrangência e o leque de possibilidades que permite, inclusive de um controle que não necessariamente passe pela propriedade privada direta da terra, remetendo a formas de control grabbing, como na sugestão de $\mathrm{N}$. Peluso e C. Lund (2011). Há um debate sobre a abrangência ou limitação tanto conceitual como temporal a ser aplicada ao termo, de modo que o caráter de novidade de uma corrida mundial por terras averiguado desde a crise financeira de 2007/2008, às vezes é remetido à alta dos preços de alimentos e commodities, a partir de 2004/2005, e em outras abordagens o conceito é ampliado para fenômenos anteriores. Nessa disputa pela interpretação dos processos, houve desde estudos do Banco Mundial (DEININGER, BYERLEE, LINDSAY, NORTON, SELOD e STICKLER, 2011) estimulando e orientando a compra de terras por empresas e países, passando por estudos mais críticos como os da FAO (GÓMEZ, 2011) restringindo o fenômeno à estrangeirização, e até mesmo formulações que tentaram "trazer de volta o capital à análise" e chegaram a uma abrangente definição como essa:

In short, contemporary land grabbing is the capturing of control of relatively vast tracts of land and other natural resources through a variety of mechanisms and forms involving large-scale capital that often shifts resource use to that of extraction, whether for international or domestic purposes, as capital's response to the convergence of food, energy and financial crises, climate change mitigation imperatives and demands for resources from new hubs of global capital (BORRAS JR., KAY, GÓMEZ e WILKINSON, 2012, p. 405).

Trata-se, pois, de vasta literatura recente que não se vale necessariamente de uma fundamentação marxiana ou marxista (ver BOECHAT, PITTA e TOLEDO, 2017). No entanto, o termo land grabbing, segundo White, Borras Jr., Hall, Scoones, Wolford (2012, p. 621), foi primeiramente concebido pelo próprio Karl Marx (1985), no acima referido capítulo sobre "A assim chamada acumulação primitiva". Desse modo, retomamos esta referência para conceber o termo em questão como parte dos muitos expedientes do processo de monopolização dos meios de produção, produzindo simultaneamente a propriedade do capital, da terra e da força de trabalho fetichistamente como mercadorias que rendem aos seus proprietários rendimentos distintos e aparentemente autônomos. 
Particularmente, a expropriação da população em relação à terra (meio de produção não produzido) é o que caracterizaria o que se deu para o caso inglês, tratado ali por Marx.

Retomando e ampliando a conceituação de Marx dos mecanismos de acumulação primitiva, aliado a uma leitura luxemburguista da expansão capitalista sobre meios nãocapitalistas, David Harvey é um importante teórico que também influencia o debate sobre land grabbing (ver SASSEN, 2013; HALL, 2013; BRENT, 2015), permitindo uma comparação crítica entre as práticas atuais e pretéritas de espoliação:

Um exame mais detido da descrição que Marx faz da acumulação primitiva revela uma ampla gama de processos. Estão aí a mercadificação e a privatização da terra e a expulsão violenta de populações camponesas; a conversão de várias formas de direitos de propriedade (comum, coletiva, do Estado etc.) em direitos exclusivos de propriedade privada; a supressão dos direitos dos camponeses às terras comuns [partilhadas]; a mercadificação da força de trabalho e a supressão de formas alternativas (autóctones) de produção e consumo; processos coloniais, neocoloniais e imperiais de apropriação de ativos (inclusive de recursos naturais); a monetização da troca e a taxação, particularmente da terra; o comércio de escravos; e a usura, a dívida nacional e em última análise o sistema de crédito como meios radicais de acumulação primitiva. O Estado, com seu monopólio da violência e suas definições da legalidade, tem papel crucial no apoio e na promoção desses processos (...). Todas as características da acumulação primitiva que Marx menciona permanecem fortemente presentes na geografia histórica do capitalismo até os nossos dias (HARVEY, 2001, p. 121).

Ressaltando a qualidade violenta das referidas práticas de acumulação primitiva, o autor parece igualar processos que estavam ocorrendo na Inglaterra com aqueles que ocorriam no Brasil em formação, como a escravidão, perdendo com isso as suas particularidades. Como mostraria Maria Sylvia de Carvalho Franco (1984), na Colônia, entretanto, a expropriação significativa do "povo" se dava em relação a seu próprio corpo, fundando uma produção de mercadorias que se exteriorizava para o mercado externo ao invés de ser consumida internamente por um "povo" confrontado a uma realidade de terras abundantes e acesso potencialmente livre aos meios de produção. Incorria-se, assim, ao contrário, numa espécie de labor grabbing, que sustentava pelo escravismo a separação entre terra e trabalho em favor do capital. Não se trata, como se vê, de mero capricho a proposição do termo, mas de relevante necessidade de caracterização de mecanismos particulares distintos de mobilização do trabalho.

CAMPO-TERRITÓRIO: revista de geografia agrária, v. 13, n. 31, p. 57-82, dez., 2018 
Assim, enquanto as práticas de land grabbing separavam à força a população do campo de seus meios de vida, mobilizando forçadamente o trabalhador, deixando-lhe apenas a propriedade da sua força de trabalho para ser negociada "livremente" em troca de salário, as práticas de labor grabbing, por outro lado, expropriavam a propriedade da força de trabalho do próprio trabalhador, impedindo-o por meio da violência direta de se apossar "livremente" de terras relativamente disponíveis no contexto colonial. Isso seria o que revelaria, para Marx (1985, cap. 25), o segredo escondido por trás da liberdade do trabalhador, restrita a escolhas dentro da forma mercadoria, não podendo escolher deixar de trabalhar e, com isso, deixar de valorizar o valor. Isto é, sem expropriação não há acumulação de capital, e uma expropriação radical como a do escravismo revela que a liberdade do trabalhador assalariado é apenas relativa e limitada, posto que assentada sobre outras formas de expropriação. Podemos, assim, centrar o trabalho no debate sobre land grabbing, como o faz Tania M. Li (2011), apresentando, de nossa parte, a discussão sobre o escravismo colonial não como modo de produção à parte ou como arcaísmo, mas como espécie de radicalização da expropriação como fundamento da acumulação de capital.

O trabalho escravo adquiriria conotação ainda mais nefasta à medida que o tráfico negreiro era um dos ramos mais rentáveis da colonização (NOVAIS, 2005) bloqueando a possibilidade de autonomização dos colonos portugueses perante à Metrópole pela escravização de nativos. Organizava-se o fornecimento de escravizados desde a África, evidenciando uma relação intercolonial no Atlântico Sul (ALENCASTRO, 2005) que produzia mercadorias em regiões tropicais organizadas até certo ponto como “arquipélagos" (SEABRA e GOLDENSTEIN, 1982) ligados ao comércio metropolitano, e apenas parcialmente entre si. Estima-se que, entre os séculos XVI e XIX, cerca de 11 milhões de africanos tenham sido trazidos como escravos para a América, sendo quase 40\% destes para a Colônia portuguesa (LOVEJOY, 2002, p. 368), embora estimativas mais recentes apontem para um número ainda superior, de cerca de 12,5 milhões e 45\%, respectivamente (<slavevoyages.org $>$ ).

Muitos meandros históricos levarão ao questionamento dessa forma de colonização do Antigo Regime, assente no labor grabbing, e não cabe retomar aqui a passagem em seus pormenores, senão remeter a elementos básicos e fundamentais da inflexão histórica. Citamos acima, por exemplo, brevemente a generalização do 
"preconceito de humanidade" (MARX, 1985, p. 65) promovido pelo assalariamento na Inglaterra e pelos ideais revolucionários do liberalismo oitocentista. Esta generalização incorreria ainda no questionamento do bloqueio à liberdade, explícito na escravidão. Culminando na queda do "exclusivo metropolitano", tendo como marco a vinda da família real para o Brasil, em 1808, e na posterior abertura dos portos às nações "amigas", seguida da Independência em 1822, esse questionamento, com efeito, imporia nova dinâmica para a colonização.

A separação em curso entre território colonial e Estado Absolutista metropolitano colocava a questão de uma gestão interna do território nacional. Para Antonio Carlos Robert Moraes (1998), a partir do século XIX, gradativamente passava a se conceber o território da colonização como território do Estado nacional, que vê os sertões e aquilo que ainda não foi efetivamente apropriado como seus "fundos territoriais", como reservas para a territorialização futura. Pôde-se pensar, a partir de então, numa "longa liquidação do colonial" (PRADO Jr., 1969) ou numa gradativa "internalização da metrópole" (DIAS, 2009) implicando em outro olhar sobre o território. Assim, retomando a interpretação que atribuía sentido à colonização pela produção de mercadorias tropicais em grandes explorações com trabalho escravo e monopólio metropolitano, teríamos a queda de um primeiro pilar do sistema colonial do Antigo Regime (NOVAIS, 2005) com a Independência, mas restaria repensar as condições de produção de mercadorias no território nacional e se a sua destinação seguiria se dando para o mercado exterior.

\section{Região entre o labor grabbing e o land grabbing}

$\mathrm{Na}$ explicação da "via inglesa" de desenvolvimento da agricultura, a modernização pautou-se, como dito, pela expropriação mediante land grabs que impunham a separação entre trabalhador e terra, movendo a "libertação" de ambos antes fundidos na figura de camponês (MARX, 1986). Promovendo, com isso, um processo de autonomização das categorias de terra e trabalho. Esta libertação "negativa" do trabalhador em relação aos meios de produção se tornava pressuposto de sua liberdade "positiva" para ir e vir, escolher onde e com quem trabalhar, porque, como vimos, ele manteria a propriedade de sua força de trabalho, apenas alugando-a no mercado (GAUDEMAR, 1977). Assim, terra cativa se articula a trabalho livre. Inversamente, na 
Colônia, a abundância de terras ocupáveis implicara na escravidão, sendo o trabalhador aí ainda mais radicalmente expropriado. A questão que surgiria ao longo do século XIX seria exatamente como acumular capital com o crescente questionamento a tais práticas de labor grabbing em realidades nas quais a própria dinâmica do capitalismo não fora suficiente para realizar o land grabbing de todo o território.

É dentro deste debate que surge o incipiente planejamento de Estado da época. Ele se organiza a partir da experiência frustrada de capitalistas ingleses tentando reproduzir suas empresas nas colônias, relatada por E. G. Wakefield (2001) e levandolhe à proposição de uma "teoria da moderna colonização" (MARX, 1985, Livro I, cap. 25). Tratava-se de pensar em como evitar a perda dos investimentos pela falta de trabalhadores que preferiam ocupar terras na fronteira a se oferecer no mercado. A falta relativa de trabalhadores implicava em aumento dos salários e diminuição da mais-valia, limitando a acumulação. A solução sugerida por Wakefield se assentava na seguinte ação do Estado: promulgar uma legislação fundiária, criando artificialmente a escassez de terras. Com isso, o Estado deveria regular as posses, enquadrando as terras sobrantes como devolutas de propriedade estatal, a serem revendidas para formar um fundo público de fomento à imigração de trabalhadores europeus. O modelo de colonização sistemática de Wakefield foi longamente debatido no Parlamento brasileiro durante a década de 1840 , culminando na legislação fundiária (Lei no. 601) e na proibição do tráfico (Lei Eusébio de Queiroz), ambas de 1850 (COSTA, 1998; LIMA, 1990).

Embora também inspirando os Homestead Acts, promulgados nos EUA nas décadas seguintes e responsáveis diretos pela organização da "corrida para o Oeste" no país (COSTA, 1999), o plano de colonização de Wakefield, como implantado no Brasil, deparar-se-ia com uma realidade em que o Estado não procedeu efetivamente à discriminação, regularização e venda de terras. A Igreja Católica seria incumbida de registrar as posses num primeiro momento. Posteriormente, coronéis receberiam ou controlariam nomeações dos cartórios de registros, reforçando o seu poder local e gerenciando todo tipo de disputa fundiária em favor de aliados (BOECHAT, 2014).

O coronelismo surge, pois, como a faceta contraditória da aplicação da colonização sistemática. Particularmente para o Brasil, a Guarda Nacional aparece como forma institucional tanto do Estado nacional em formação, bem como do poder regional. Fundado em 1831, esse braço civil do exército representava por meio de concessões de 
patentes a territorialização do próprio Estado, embora delegando sua autoridade a líderes locais, latifundiários e comerciantes que se tornavam coronéis, podendo recrutar "soldados". Se a definição weberiana do Estado moderno exige o monopólio estatal da violência era justo esse monopólio que era aparentemente "terceirizado" para uma oligarquia regional. Tal instituição parece marcar formas singulares de reprodução do capital e de luta de classes, em que econômico e político se fundem, compondo um entendimento profícuo do conceito de região (OLIVEIRA, 2008, p. 148):

Uma "região" seria, em suma, o espaço onde se imbricam dialeticamente uma forma especial de reprodução do capital e, por consequência, uma forma especial de luta de classes, onde o econômico e o político se fusionam e assumem uma forma especial de aparecer no produto social e nos pressupostos da reposição.

Fica explícita a fusão do econômico com o político na figura do coronel que personifica tanto a propriedade fundiária, como o capital e também o Estado. Com a Proclamação da República, em 1889, semelhantes mecanismos de poder que ordenavam disputas territoriais seriam aplicados na centralização de votos por coronéis de níveis locais, elevando gradativamente as tensões e disputas regionais à escala nacional, de modo que a Revolução de 1930 procuraria impor o desarmamento dos coronéis, a centralização e o reforço do exército nacional e a institucionalização de uma Justiça Eleitoral autonomizada, entre outras mudanças (LEAL, 1976; FAORO, 1989). Desse modo, a Guarda Nacional pode ser compreendida como forma institucional reconhecida de domínio territorial do Estado brasileiro até o fim da Primeira República (1889-1930), perdurando até 1924 e sendo efetivamente desarmada apenas pelas tropas getulistas.

Neste contexto, ocorreu a expansão de lavouras cafeeiras pelo Sudeste brasileiro. Primeiro, pelo Vale do Paraíba, com trabalho escravo oriundo do tráfico negreiro e, após 1850, com os mesmos sendo comprados de regiões escravistas decadentes do Norte e Nordeste, para então seguir pelo Oeste Paulista, com trabalho livre recrutado sobretudo na Europa mediterrânea, constituindo-se uma cafeicultura que se expandia mas se diferenciava social e produtivamente em duas regiões contrapostas (BEIGUELMAN, 2005). O Parlamento provincial de São Paulo aprovaria em 1862 o aporte de subsídios a investimentos em ferroviárias enquanto dava suporte ao extermínio indígena ${ }^{1}$ no interior da província, viabilizando a expansão da frente pioneira (MONBEIG, 1998) conforme 
pagava as passagens de imigrantes europeus vindos para trabalhar no cafée, então exportado para países industrializados, estimulando o trabalho industrial.

A simultaneidade da questão da falta de braços para a lavoura com uma questão indígena bloqueada ou tratada como entrave à expansão da frente pioneira do café há que ser ressaltada, mas haveria outros elos obscurecidos. Enquanto o coronelismo impunha sua ordem à ocupação das terras, direcionando as ferrovias para fazendas e vilas de aliados, em detrimento de outros, relacionava-se também com o capital financeiro e industrial inglês por meio das casas comissárias e das companhias ferroviárias e exportadoras (BOECHAT, 2014). As ligações entre a região e o mercado global ficam claras quando observamos a mobilização do capital e do trabalho sobreacumulado nas economias industrializadas (HARVEY, 2005).

Realmente distinto do escravismo, o sistema de trabalho do colonato da cafeicultura pós-colonial não poderia, porém, ser visto como mero trabalho assalariado, senão em controversas análises. O trato de um dado número de cafeeiros era colocado sob a responsabilidade do imigrante e sua família, mas lhes era permitido no plantio intercafeeiro colher alimentos para si e para a venda. Por este contrato, recebia-se salário monetário regular e uma proporção da colheita, além do acesso a uma casa e parte de um pasto no interior da fazenda. Essa era uma das formas sociais contraditórias na qual terra, trabalho e capital não existiam separados, combinando rendimentos (renda, salário e lucros) e se reproduzindo como trabalho (ou exploração) familiar que não se individualizava por completo, embora conduzido pelo pai numa relação patriarcal.

Muitas outras relações sociais de produção tomariam formas particulares, tais como o aviamento na extração de seringa na Amazônia (GONÇALVES, 2005), as formas de morador na produção de cana-de-açúcar no Nordeste (OLIVEIRA, 2008), os garimpeiros da Chapada Diamantina (TOLEDO, 2008) ou os agregados da fazenda pecuária que se espalhava pelos sertões (LEITE, 2015), embora no limite se assemelhassem a certos elementos apontados para o colonato. A forma de trabalho na fronteira agrícola brasileira entre as décadas de 1870 e 1960 parece ser, então, um trabalho livre com acesso aos meios de produção, cujos termos eram negociados com coronéis locais.

Sugerimos, portanto, pensar a região, conformando tais particularidades, como parte do processo de territorialização de relações sociais de produção nas quais as práticas

CAMPO-TERRITÓRIO: revista de geografia agrária, v. 13, n. 31, p. 57-82, dez., 2018 
de escravismo sans phrase foram sendo gradativamente bloqueadas e nas quais a liberdade contraditória do trabalhador era relativizada pela sua forma de inserção mediada, seja cultural seja familiar ou politicamente. Essa liberdade foi mecanismo central para o questionamento na prática da colonização antes assentada na escravidão, permitindo e incitando a disputa política que levaria à Abolição, em 1888, e à Proclamação da República, em 1889. A transição do labor grabbing ao land grabbing no interior do Brasil, todavia, não estaria completa até a modernização da agricultura do pósguerra. Ao lado dela, um forte processo de industrialização e de urbanização ${ }^{3}$ caracterizaria uma transformação social considerável.

O olhar para aquelas formas de relações sociais de produção, informado pelo conceito de autonomização, tal qual sugerido por Marx (1986) na "Gênese da renda fundiária capitalista", permite, para além da clássica teorização da passagem do trabalho escravo para o trabalho livre, orientar a interpretação do processo de modernização como aquele que procura instalar a separação fetichista de mercados supostamente autônomos de terra, trabalho e capital, ao lado da separação igualmente fetichista e sempre questionável na prática entre a economia e a política.

\section{Planejamento de Estado e a emergência da questão regional}

Francisco de Oliveira (2008), embora reconhecendo a filiação conceitual do termo região à geografia, lidaria por fim com a tensão colocada pela apropriação do mesmo pelo planejamento do Estado, que se colocava como planejamento regional:

O planejamento surge aqui como uma "forma" da intervenção do Estado sobre as contradições entre a reprodução do capital em escala nacional e regional, e que tomam a aparência de conflitos interregionais; o planejamento não é, portanto, a presença de um Estado mediador, mas, ao contrário, a presença de um Estado capturado ou não pelas formas mais adiantadas da reprodução do capital para forçar a passagem no rumo de uma homogeneização ou, conforme é comumente descrito pela literatura sobre planejamento regional, no rumo da “integração nacional”. (OLIVEIRA, 2008, p. 149).

O estruturalismo que embasava tal planejamento passaria a quantificar dados prédeterminados para apontar desvios e propor intervenções nas regiões. Recusando tratar o papel modernizador do Estado como "neutro", o autor enfocaria a existência de conflitos 
entre formas de acumulação, sendo o Estado instrumento de hegemonização. Com isso, podemos indicar que o surgimento de uma burocracia é parte necessária da constituição de um Estado que se autonomiza do capital, como instância com lógicas não total e diretamente determinadas por este nem visando apenas à acumulação (ver KURZ, 1998). A formação de técnicos e quadros para os setores do Estado aparece como desdobramento lógico de uma diferenciação da forma regional, pautada em "compromissos" coronelistas (LEAL, 1976). Assim, a universidade caminha pari passu essa (trans-)formação do Estado. A formação das condições para formar uma burocracia que personifica o Estado é elemento significativo da passagem para outra forma de dominação socialmente legítimada (BOECHAT, 2014; LEITE, 2015).

A partir deste processo, a "região" seria re-significada pelo Estado e suas instâncias, caminhando para a conformação hoje naturalizada de regiões integradas no plano nacional - Norte, Sul, Centro-Oeste, Sudeste e Nordeste - oriundas do processo de territorialização e daquele de integração nacional que dele emerge, assimila-o e o modifica. Numa perspectiva de intervenção, as diferenças decorrentes de relações sociais de produção particulares parecem ser reduzidas fetichista e tendencialmente a desigualdades de alocação de fatores, introduzindo na tecnocracia que supostamente orienta tal intervenção a chamada questão regional. Porém, ela não se resume a isso.

Assim, o período entre 1930 e 1970, seria marcado por um conflito que evidencia a apropriação parcial de excedentes para a industrialização, sem haver ruptura completa com as relações de produção antes vigentes (STOLCKE, 1986). De um lado, permitia-se a constituição gradativa do mercado de trabalho nacional, em prol da industrialização do Centro-Sul; de outro, as regiões se re-situavam funcionalmente permitindo a manutenção da acumulação pelo fornecimento de alimentos e de matérias-primas, liberando mão de obra, criando mercado e transferindo e recebendo capitais (CASTRO, 1969, p. 94-96). Promovia-se a modernização retardatária (KURZ, 2000), voltada a fomentar a industrialização nacional numa corrida para alcançar os patamares de produtividade das economias centrais. A quebra parcial das relações político-econômicas que a organizavam permite um direcionamento de parte da acumulação regional para o planejamento nacional da industrialização (OLIVEIRA, 1977). Por outro lado, seria necessária uma conjuntura internacional favorável para permitir uma exportação de capitais que promovessem um efetivo desdobramento da indústria (MELLO, 2008).

CAMPO-TERRITÓRIO: revista de geografia agrária, v. 13, n. 31, p. 57-82, dez., 2018 
Estamos, assim, sugerindo que a "integração nacional", que tem como "teleologia" (COSTA, 2013) a ruptura das relações de poder e a transformação das formas particulares de reprodução das relações sociais de produção da região, irá formular no patamar (nacional) de discussão uma questão regional. Esta se desdobraria em uma questão migratória e numa questão fundiária que iriam compor a questão agrária e a questão urbana das disputas pelos rumos e sentidos da modernização. Recuperamos aqui a sugestão de Carlos Vainer (1984), para quem se impõe gradativamente uma perspectiva que se dirige ao Estado como um "médico da sociedade" a buscar curar "patologias de que o organismo social é portador", sendo que estas fomentam discursos oficiais diversos mas sempre voltados para o "encobrimento-deslocamento" das reais causas das "patologias": "Que a questão racial ceda lugar à questão regional, que a questão dos braços para a agricultura seja superada pela questão urbana, eis fenômenos que estão a sinalizar a aparição de novas formas de controle do trabalho no espaço" (VAINER, 1984, p. 42).

\section{Considerações finais}

Reiteramos aqui que Oliveira (2008) falara de uma "homogeneização" das regiões em "zonas de localização diferencial" integradas nacionalmente, sendo duramente criticado pela geografia brasileira por não observar a reposição constante das diferenças na produção do espaço (LENCIONI, 1999). Contudo, há que se atentar para a lógica subjacente à sua formulação que não negava a diferença na homogeneidade, sendo esta antes marcada por desigualdades. Mas, afinal, o que se homogeneizaria? A "abertura" da região implicava na autonomização entre o econômico e o político e, logo, implicava também na mobilização do trabalho. Para Oliveira (2008), o "sentido profundo" do processo poderia ser apontado como o assalariamento, expresso na migração de trabalhadores oriundos das regiões para a industrialização e urbanização nacionais. Todavia, ele afirmara que a "acumulação primitiva" se estruturava nacionalmente pela “elaboração de periferias” (OLIVEIRA, 2003, p. 43), o que implicava num duplo sentido tanto de um trabalhador instalado nas periferias urbanas como na expansão do capitalismo para a frente pioneira, reproduzindo condições "primitivas" de acumulação e repondo relações de trabalho não assalariadas.

CAMPO-TERRITÓRIO: revista de geografia agrária, v. 13, n. 31, p. 57-82, dez., 2018 
Estivemos sugerindo, no entanto, que uma região específica esteve atrelada a uma colonização sistemática na qual limitações à "mobilidade perfeita" do trabalho se davam na prática, enquanto, ao contrário, o seu próprio fundamento promovia mobilidade. Como vimos, a colonização sistemática sustentara a promulgação de leis e políticas de imigração, constituindo uma superpopulação relativa capaz de permitir a acumulação de capital no contexto da existência de fronteiras abertas. Assim, compreendemos uma intenção latente de se permitir o assalariamento na referida legislação e na sistematização do colonato; intenção esta "torcida pela realidade" (FAORO, 1989) em que foi empregada. O colono fundia as categorias do capital (terra, trabalho e capital) e sua "modernização" implicaria na autonomização daquelas categorias em diferentes personas. A proposição aqui é de um entendimento da modernização retardatária em sua faceta regional que recuse o dualismo explícito, por exemplo, no próprio Oliveira (2003), posto concebermos as relações na região como eminentemente modernas, e não feudais, tradicionalistas ou primitivas. Modernização é aqui tida como processo de autonomização do capital. $\mathrm{O}$ assalariamento do trabalhador é um caminho possível para isto se dar, mas não o único. A região foi momento da territorialização do capital na realidade dada, mas não seguirá necessariamente reposta, de modo que urbanização, industrialização e financeirização irão conferir condicionamentos novos e críticos à reprodução social no campo e na cidade ${ }^{4}$.

São marcos da passagem final do percurso recuperado as legislações promulgadas na década de 1960. O Estatuto do Trabalhador Rural (Lei no. 4.212, de 1963) e o Estatuto da Terra (Lei no. 4.504, de 1964), colocar-se-ão como releitura nacional da territorialização do Estado nacional e do capital, que haviam tido até então como parâmetro as políticas de colonização sistemática. Se a Lei de Terras (Lei no. 601, de 1850) sintetizava, como vimos, um projeto de colonização assentado no monopólio de classe sobre a terra (land grabbing), que se juntava a uma série de medidas que bloqueavam a escravidão (labor grabbing) - Lei Eusébio de Queiroz (Lei no. 581, de 1850), Lei do Ventre Livre (Lei no. 2.040, de 1871), Lei do Sexagenário (Lei 3.270, de 1885), e Lei Áurea (Lei no. 3.353, de 1888) -, as novas legislações, da década de 1960, não negariam esta qualidade fundamental da acumulação de capital na agricultura moderna, mas se voltariam contra elementos da colonização sistemática, sobretudo formas regionais de trabalho. A regulamentação da parceria agrícola e, pois, do acesso à

CAMPO-TERRITÓRIO: revista de geografia agrária, v. 13, n. 31, p. 57-82, dez., 2018 
terra e outras modalidades de rendimento do trabalho agrícola, no interior do Estatuto da

Terra, sugerem um planejamento em favor do assalariamento, fator que contribuiu para a expulsão massiva de agregados e parceiros das fazendas (SILVA, 1999), embora o Estatuto também regulasse a Reforma Agrária e políticas de colonização. A questão regional, repensada aqui em termos formativos e críticos, parecia dar lugar, portanto, a uma tensa questão agrária, ainda hoje distante de ser equacionada. Sugerimos, assim, que o que estava em jogo no momento em que se iniciaria o período ditatorial (1964-1985) era o fim da quadratura histórica da colonização sistemática nos termos da região. $\mathrm{O}$ quanto este planejamento foi bem-sucedido e como ele se colocou em prática afirmando esse novo sentido ou contradizendo-o é algo que deve ser pensado.

\section{Notas}

1 Dados do FUNAI (<funai.gov.br>) apontam para a existência, no século XVI, de cerca de um milhão de indígenas no interior da Colônia, ao lado de cerca de 2 milhões que viveriam no litoral, ao passo que o IBGE estima que onde seria o estado de São Paulo haveria aproximadamente 146 mil indígenas de 8 grupos distintos. Em 1957, a população indígena total chegou ao seu patamar mais baixo, em torno de 70 mil indivíduos, 65 mil deles no interior, segundo a FUNAI, tendo havido um aumento significativo deste então destes contingentes ( 817 mil índios contabilizados no Censo de 2010, sendo 545 mil no interior e 41 mil em São Paulo; IBGE, 2000; IBGE, 2010).

$2 \quad$ Entre 1822 e 1980, 5.827.237 imigrantes aportaram no Brasil, segundo dados do IBGE (2000), sendo que cada período, entre 1890 a 1900, entre 1901 e 1920, e entre 1920 e 1940 , registrou respectivamente 1.143.902, 1.466 .388 e 1.269.270 entradas. Portanto, no auge da expansão cafeeira 3.879.560 imigrantes ingressaram oficialmente no Brasil, num período de 50 anos. A maior parte dos quais se dirigiu para as lavouras cafeeiras e para as cidades do Sudeste, muitos dos quais com passagens pagas pelo governo de São Paulo (Boechat, 2009).

Apenas nas estatísticas dos anos 1960, a indústria supera a agricultura em participação no PIB nacional e a população urbana supera a população rural (IBGE, 2000).

4 O próprio Oliveira (2006), em texto relativamente mais recente, afirmaria que a forma de reprodução da periferia urbana pela autoconstrução, a rebaixar os cursos de reprodução da força de trabalho permitindo o rebaixamento do seu próprio salário e, com isso, promovendo a industrialização, modificarase pela revolução tecnológico-científica na linha de produção. A relação da periferia com a industrialização parece ter se rompido e o trabalho informal e precário se tornaria a regra, como reconhece o sociólogo apenas parcialmente.

\section{Referências}

ALENCASTRO, Luís Felipe de. O trato dos viventes: formação do Brasil no Atlântico Sul. São Paulo: Companhia das Letras, 2005. (544 p.).

BEIGUELMAN, Paula. A formação do povo no complexo cafeeiro - aspectos políticos. São Paulo, Edusp, 2005. (280 p.). 
BOECHAT, Cassio A.; PITTA, Fábio T.; TOLEDO, Carlos A. Land grabbing e crise do capital: possíveis intersecções dos debates, Geographia, Niterói, v. 19, n. 40, p. 75-91, mai./ago., 2017.

O colono que virou suco: terra, trabalho, Estado e capital na modernização da citricultura paulista. 569 f. Tese (Doutorado em Geografia Humana). Faculdade de Filosofia, Letras e Ciências Humanas, USP, São Paulo, 2014.

Região do colonato: mobilização do trabalho e autonomização do capital na área de Olímpia (1857-1964) do Oeste Paulista. 311 f. Dissertação (Mestrado em Geografia Humana). Faculdade de Filosofia, Letras e Ciências Humanas, USP, São Paulo, 2009.

BORRAS JR., Saturnino, KAY, Cristobal; GÓMEZ, Sergio; WILKINSON, John. Land grabbing and global capitalist accumulation: key features in Latin America. Canadian Journal of Development Studies, Ottawa, v. 33. N. 4, p. 402-416, 2012.

BRANT, Vinícius Caldeira. Do colono ao bóia-fria: transformações na agricultura e constituição do mercado de trabalho na Alta Sorocabana de Assis. Estudos CEBRAP, São Paulo, n. 19., p. 37-91, 1976.

BRENT, Zoe W. Territorial restructuring and resistance in Argentina. The Journal of Peasant Studies, Londres, v. 42, n. 3-4, p. 671-694, 2015.

BUAINAIN, Antonio M.; ALVES, Eliseu; SILVEIRA, José M.; NAVARRO, Zander. Sete teses sobre o mundo rural brasileiro. In: BUAINAIN, A. M.; ALVES, E.; SILVEIRA, J. M.; NAVARRO, Z. (org.) O mundo rural no Brasil do século 21. Brasília: Embrapa, 2014, p. 1.159-1.186.

CARNEIRO, Maria J., 2008. Rural como categoria de pensamento. Ruris, Campinas, v. 2, n. 1., 2008, p. 9-38.

CASTRO, Antonio Barros de. Sete ensaios sobre a economia brasileira. Rio de Janeiro: Forense, 1969, 193 p.

CLEMENTS, Elizabeth Alice; FERNANDES, Bernardo Mançano. Land grabbing, agribusiness and the peasantry in Brazil and Mozambique. International Conference Global Land Grabbing II: Ithaca, 2012.

COSTA, Emília Viotti da. Da monarquia à república - Momentos decisivos. $7^{\mathrm{a}} \mathrm{ed}$, São Paulo: Fundação Editora da UNESP, 1999, 490 p. $560 \mathrm{p}$.

Da senzala à colônia. $4^{\text {a }}$. ed., São Paulo: Fundação Editora da UNESP, 1998, 
COSTA, Francisco de Assis. Sete teses sobre o mundo rural brasileiro: antíteses.

Revista da ABRA, Campinas, edição especial, 2013. p. 45-60.

DEININGER, K.; BYERLEE, D.; LINDSAY, J.; NORTON, A.; SELOD, H.;

STICKLER, M. In: Rising global Interest in farmland: can it yield sustainable and equitable benefits? Washington: The World Bank, 2011.

DIAS, Maria Odila S. Leite. A interiorização da metrópole e outros estudos. $2^{\mathrm{a}}$ ed., São Paulo: Alameda, 2009, 325 p.

D’INCAO, Maria Conceição. O “bóia-fria”: acumulação e miséria. Petrópolis: Vozes, 1979.

FAORO, Raymundo, 1989. Os donos do poder: formação do patronato político brasileiro. $8^{a}$ ed., São Paulo: Globo, 1989, 750 p.

FRANCO, Maria Sylvia de Carvalho. 1997. Homens livres na ordem escravocrata. São Paulo: Fundação Editora da UNESP, 1997, 253 p.

Organização social do trabalho no período colonial. In: PINHEIRO, Paulo Sergio. Trabalho escravo, economia e sociedade. São Paulo: Paz e Terra, 1984, p. 143-192.

FREYRE, Gilberto. Casa-Grande \& Senzala - introdução à história patriarcal no Brasil. Rio de Janeiro: Record, 2000, 668 p.

FURTADO, Celso. Formação econômica do Brasil. São Paulo: Brasiliense, 2000, 276 p.

GAUDEMAR, Jean Paul de. Mobilidade do trabalho e acumulação do capital. Lisboa: Estampa, 1977, 405 p.

GÓMEZ, Sergio. Dinámica del mercado de la tierra em América Latina y el Caribe. Relatório de Pesquisa. Santiago: FAO, 2011.

GONÇALVES, Carlos Walter Porto. Amazônia, Amazônias. Rio de Janeiro: Contexto, 2005, $178 \mathrm{p}$.

HALL, Derek. Primitive accumulation, accumulation by dispossession and the global land grab. Third World Quarterly, v. 34, n. 9, 2013, p. 1582-1604.

HARVEY, David. A produção capitalista do espaço. São Paulo: Annablume, 2005, $249 \mathrm{p}$.

O novo imperialismo. São Paulo: Loyola, 2001, 201 p.

HOLANDA, Sergio Buarque de. Raízes do Brasil. São Paulo: Companhia das Letras, $1995,256 \mathrm{p}$.

CAMPO-TERRITÓRIO: revista de geografia agrária, v. 13, n. 31, p. 57-82, dez., 2018 
IBGE. Brasil 500 anos de povoamento. Disponível em: <brasil500anos.ibge.gov.br>. Acesso em 09 de agosto de 2018.

IBGE. Censo de 2010 - resultados. Disponível em: <censo2010.ibge.gov.br>. Acesso em 09 de agosto de 2018.

JACKSON, Luiz Carlos. Tensões e disputas na sociologia paulista (1940 - 1970).

Revista Brasileira de Ciências Sociais, v. 22, n. 65, 2007, p. 33-49.

KURZ, Robert. A falta de autonomia do Estado e os limites da política. In: KURZ, Robert. Os últimos combates. Petrópolis: Vozes, 1998, p. 91-118.

O colapso da modernização - Da derrocada do socialismo de caserna à crise da economia mundial. Rio de Janeiro: Paz e Terra, 2000, 231 p.

LEAL, Victor Nunes. Coronelismo, enxada e voto - O município e o regime representativo no Brasil. São Paulo: Alfa-Ômega, 1976, 276 p.

LEITE, Ana Carolina Gonçalves. O campesinato no Vale do Jequitinhonha: da sua formação no processo de imposição do trabalho à crise da (sua) reprodução capitalista. 762 f. Tese (Doutorado em Geografia Humana). Faculdade de Filosofia, Letras e Ciências Humanas, USP, 2015.

Acumulação de capital, mobilização regional do trabalho e coronelismo no Brasil. Cuadernos de Geografía, v. 23, n. 1, 2014, p. 75-92.

LENCIONI, Sandra. Região e geografia. São Paulo: Editora da Universidade de São Paulo, 1999, 215 p.

LI, Tania Murray. Centering labor in the land grab debate. The Journal of Peasant Studies, v. 38, n. 2, 2011, p. 281-298.

LOVEJOY, Paul E. A escravidão na África: uma história de suas transformações. Rio de Janeiro: Civilização Brasileira, 2002, 467 p.

LIMA, Ruy Cirne. Pequena história territorial do Brasil: Sesmarias e terras devolutas. São Paulo: Secretaria de Estado da Cultura, 1990, 112 p.

LIPIETZ, Alain. O capital e seu espaço. São Paulo: Nobel, 1988, 209 p.

LUXEMBURG, Rosa. Acumulação de capital: contribuição ao estudo do imperialismo. São Paulo: Nova Cultural, 1984, 418 p.

MARTINS, José de Souza. O cativeiro da terra. São Paulo; Hucitec, 1998, 157 p.

CAMPO-TERRITÓRIO: revista de geografia agrária, v. 13, n. 31, p. 57-82, dez., 2018 
MARX, Karl. O Capital - crítica da Economia Política. Vol. I. São Paulo: Nova Cultural, 1985, $301 \mathrm{p}$.

$1986,335 \mathrm{p}$.

O Capital - crítica da Economia Política. Vol. IV. São Paulo: Nova Cultural,

MELLO, João Manoel Cardoso de. O capitalismo tardio. Campinas: Ed. FACAMP e EdUnesp, 2009, 150 p.

MONBEIG, Pierre. Pioneiros e fazendeiros de São Paulo. São Paulo: Hucitec/Polis, 1998, 392 p.

MORAES, Antonio. Carlos Robert de. Geografia: pequena história crítica. São Paulo: Annablume, 2003, 130 p.

Ideologias geográficas: espaço, cultura e política no Brasil. São Paulo:

Hucitec, 1998, 156 p.

NOVAIS, Fernando. Portugal e Brasil na crise do antigo sistema colonial (17771808). São Paulo: Editora Hucitec, 2005, 420 p.

OLIVEIRA, Ariovaldo U. de. Modo capitalista de produção e agricultura. São Paulo: Ática, 1987, 88 p.

A questão da aquisição de terras por estrangeiros no Brasil - um retorno aos dossiês. Revista Agrária, n. 12, p. 03-113, 2010.

OLIVEIRA, Francisco de. Crítica à razão dualista; O ornitorrinco. São Paulo: Boitempo Editorial, 2003, 150 p.

. Economia da dependência imperfeita. Rio de Janeiro: Graal, 1977, 159 p.

Elegia para uma re(li)gião: Sudene, Nordeste. Planejamento e conflito de classes; Noiva da Revolução. São Paulo, Boitempo, 2008, 278 p.

O vício da virtude - autoconstrução e acumulação capitalista no Brasil. Novos Estudos, n. 74, São Paulo, 2006, p. 67-85.

. Questão regional: hegemonia inacabada. Estudos Avançados, v. 7, n. 18, a. 03, São Paulo, 1993, p. 43-63.

PELUSO, Nancy Lee; LUND, Christian. 2011. New frontiers of land control. The Journal of Peasant Studies, v. 38, n. 4, 2011, p. 667-681.

PRADO Jr., Caio. A questão agrária no Brasil. São Paulo: Brasiliense, 1979, 188 p. 
$390 \mathrm{p}$.

Formação do Brasil contemporâneo: Colônia. São Paulo: Brasiliense, 2000,

História econômica do Brasil. São Paulo: Brasiliense, 1969, 352 p.

PUNTONI, Pedro. A Guerra dos Bárbaros: Povos Indígenas e a Colonização do Sertão Nordeste do Brasil, 1650-1720. São Paulo: HUCITEC/Edusp/Fapesp, 2002, 324 p.

QUIJANO, Aníbal. Colonialidade do poder, eurocentrismo e América Latina. In:

LANDER, Edgardo. A colonialidade do saber: eurocentrismo e ciências sociais.

Perspectivas latino-americanas. Buenos Aires: CLACSO, 2005, p. 107-129.

QUEIROZ, Maria Isaura Pereira de. O mandonismo local na vida política brasileira e outros ensaios. São Paulo: Editora Alfa-ômega, 1976.

RANGEL, Ignácio M. A questão da terra. Revista de Economia Política, v. 6, n. 4, 1986, p. 71-77.

SANTOS, Milton. Por uma Geografia Nova. São Paulo: Edusp, 2008.

SASSEN, Saskia. Land Grabs today: feeding the disassembling of national territory. Globolizations, Helsinki, v. 10, n. 1, p. 25-46, 2013.

SAUER, Sergio; BORRAS Jr., Saturnino M. "Land grabbing" e "green grabbing": uma leitura da "corrida na produção acadêmica" sobre a apropriação global de terras.

Campo-Território - Revista de Geografia Agrária. Edição Especial, 2016, p. 6-42.

; LEITE, Sérgio Pereira. Agrarian structure, foreign investment in land, and land prices in Brazil. The Journal of Peasant Studies, Londres, v. 39, n. 3-4, p. 873-898, 2012.

SCHWARZ, Roberto. Um mestre na periferia do capitalismo: Machado de Assis. Rio de Janeiro: Duas Cidades/Editora 34, 2000, 256 p.

SEABRA, Manoel; GOLDENSTEIN, Lea. Divisão territorial do trabalho e nova regionalização. Revista do Departamento de Geografia, São Paulo, n. 1, 1982, p. 21 47.

SILVA, Maria Ap. Moraes. Errantes do fim do século. São Paulo: Fundação Editora da UNESP, 1999, 370 p.

SORRE, Max. Migrações e mobilidade do ecúmeno. In: SORRE, Max. Max Sorre, Geografia, São Paulo: Ática, 1984, p. 124-139.

CAMPO-TERRITÓRIO: revista de geografia agrária, v. 13, n. 31, p. 57-82, dez., 2018 
STOLCKE, Verena. Cafeicultura - homens, mulheres e capital (1850-1980). São Paulo, Brasiliense, 1986, 410 p.

TOLEDO, Carlos de Almeida. A região das lavras baianas. 245 f. Tese (Doutorado em Geografia Humana). Faculdade de Filosofia, Letras e Ciências Humanas, USP, São Paulo, 2008.

TOLEDO, Carlos de Almeida; BOECHAT, Cássio Arruda. Mobilização do trabalho e o estudo da região. Boletim Campineiro de Geografia, Campinas, v. 2, n.3, 2012, p. 448-464.

VAINER, Carlos B. Trabalho, espaço e estado: questionando a questão migratória. Cadernos IPUR, Rio de Janeiro, v. 1, n. 1, 1984, p. 6-43.

WANDERLEY, Maria Nazareth B. O mundo rural como um espaço de vida reflexões sobre a propriedade da terra, agricultura familiar e ruralidade. Porto Alegre: UFRGS Editora, 2009, 329 p.

WAKEFIELD, Edward Gibbon. A View of the Art of Colonization. Kitchner: Batoche Books, 2001, 154 p.

WHITE, Ben; BORRAS Jr., Saturnino; HALL, Ruth; SCOONES, Ian; WOLFORD, Wendy. The new enclosures: critical perspectives on corporate land deals. The Journal of Peasant Studies, v. 39, n. 3-4, 2012, p. 619-647.

Recebido em 09/08/2018.

Aceito para publicação em 22/03/2019. 